Pak. j. sci. ind. res. Ser. A: phys. sci. 2021 64A(3) 233-239

\title{
Field Investigation and Experimentation of Expansive Mortar in Dimension Stone Mining
}

\author{
Aamir Muhammad ${ }^{a}$ Ibrahim Amin ${ }^{\text {b* }}$, Muhammad Adil ${ }^{b}$ and Salim Raza \\ ${ }^{a}$ Directorate General of Mines and Minerals, Khyber Pakhtunkhwa \\ ${ }^{\mathrm{b}}$ University of Engineering and Technology, Peshawar, Pakistan
}

(received June 17, 2020; revised November 4, 2020; accepted November 5, 2020)

\begin{abstract}
Nature has blessed Pakistan with huge reserves of dimension stone that are mostly extracted through conventional mining methods. Different mechanized techniques have been tested and some give propitious results but failed to get popularity in the dimension stone sector of Pakistan. One such attempt is made in this work and a non-conventional method expansive mortar (EM) is introduce into this sector, to reduce the waste and cracks that are produced during conventional mining method (drilling and blasting). The results proclaim that expansive mortar efficiently reduced waste production and increased productivity. Through conventional method 470 MTs economical blocks were extracted from a block of 10758 cubic $\mathrm{ft}$, earning \$1121.95. In contrast, expansive mortar was applied to a block volume of $6750 \mathrm{cubic} \mathrm{ft}$, in which economical blocks extracted were weighing 489 MTs, earning \$5766.46. These encouraging figures replicate more than five-time increase in profit and high reduction in waste production.
\end{abstract}

Keywords: marble mining, conventional mining, non-conventional mining, cracks, expansive mortar

\section{Introduction}

Variety of stones, suitable for building or other industrial use are most abundantly distributed throughout Pakistan and its marble reserves are approximately 300 billion tons (Korai, 2010; SBI, 2010; Asrarullah and Hussain, 1985). 90\% of reserves are in Khyber Pakhtunkhwa Fig. 1 shows map of marble and granite locations in KPK and ex-FATA. Marble contributes $0.008 \%$ to GDP and rank $5^{\text {th }}$ among all minerals (Mansoor, 2012). Marble must fulfill certain definite condition as to strength, colour, free from cracks to be exported. Pakistan exports less than $10 \%$ of its marble extracted(Korai, 2010; SBI, 2010; SMEDA, 2010). Although the sector has a large amount of resources and maneuvering for more than half a century, the sector has not been able to develop to the desired level. This lagging behind is due to complex combination of reasons.

Huge reserves of dimension stones are present in different districts of KP i.e. Buner, Mardan, Nowshera, Malakand, Chitral and Mansehra. These marble reserves are associated with the four formations which are (Marguzar) of Alpurai group including Kashala, Saidu and Nikanai Ghar (Asrarullah and Hussain, 1985). Buner is the dominant marble galaxy with significant reserves of 1.4 billion tons, contributing to $51 \%$ of total

*Author for correspondence;

E-mail: ibrahim.min@uetpeshawar.edu.pk marble production of Pakistan (Khan et al., 2019). Mardan and Nowshera marble also play its role in the development of local industry. Mansehra and Malakand are gifted with substantial reserves of granite. Mansehra granite is of export quality and is famous in the neighboring country i.e. China.

Cutting and polishing of the stone is done in the local processing industry. The processing units is widely distributed over the province i.e. Buner 280-300 units, Mardan 80-100 units, Nowshera 60-80 units, Peshawar 80-100 with polishing facility and Swat 60-70 units. Buner and Swat has mainly cutting concentration with no polishing facility and Mardan and Peshawar with both cutting and polishing concentration. The infrastructure is improving day by day which is adding value to the stone both in local and international market (Pakistan Financial Services Sector Reform Programme (PFSSRP) Report, 2007).

There are different techniques used for the extraction of dimension stones worldwide i.e. feather and wedge method, drilling and blasting technique, acconex method, wire saw, chain saw cutting techniques, water jet cutting technique, flame jet cutting technique and slot drilling technique (Bhandari and Rother, 2001). The local industry of KP is widely using explosive for the extraction of dimension stones and wire saw in a few 
numbers of quarries with high quality of stone. Unfortunately, mechanized techniques are not enjoying its charm in the industry due to its high operating cost and low quality of dimension stone. Abundant raw material is available in the local market which is extracted through conventional method (lower extraction cost per ton), therefore, it has brought down the cost of raw marble.

Conventional technique for marble extraction. Conventional technique means the use of explosive for the extraction of dimension stones. The method adopted in the local industry of KP with its own design and

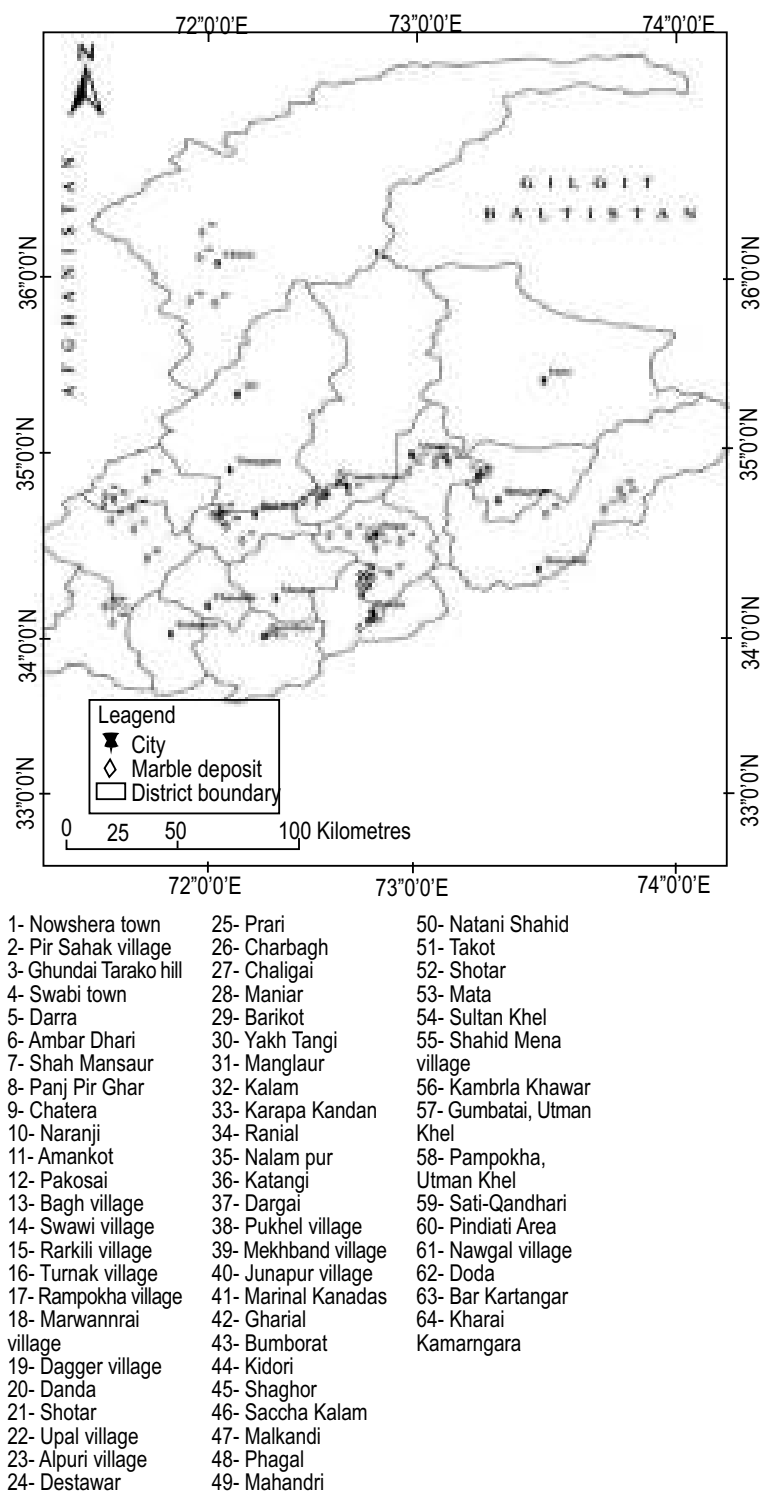

Fig. 1. Map showing marble locations in KPK \& ex-FATA (Bilqees et al., 2017). desires. Firstly, horizontal holes are drilled in the high face wall and charge with high explosives (nitroglycerine base) without calculating overburden and spacing. In the result, whole face breaks down and large amount of waste and irregular shape blocks are formed. As a result more than $70 \%$ of waste material is produced (SBI, 2010; SMEDA, 2010) which is too high than international standard 50\% (SMEDA, 2010) and is irresponsible use of non-renewable resource. Drawbacks of using blasting as extraction method are as follows;

Cracks, high percentage of waste at quarry as well as processing area, high working face, irregular shape blocks, hazardous nature

As quality of marble blocks depends on method of extraction. In Pakistan blasting for marble extraction is the norm which is damaging parent rock as well as extracted blocks and yields very less recovery (Bhandari and Rother, 2001). This is the main reason why our dimension-stone sector cannot secure its place in the international market. Lack of shares in international market is because of extraction methods where very low-quality blocks are produced. It is discouraging to note that although there are plenty of high-quality reserves available; our country has failed to conquer the market. Fig. 2 shows a view of indiscriminate blasting and high face with blasting induced cracks in quarries. The higher and hanging working faces are one of the major sources of accidents, where the workers trap in the falling faces due to gravity. It can also cause accidents, if a small stone fell down of the higher working faces.

As discussed by (Bhandari and Rother, 2001) there are number of methods for extraction of dimension stone. most of these methods are very expensive and mine operators in Pakistan or low investors with limited resourceswho cannot afford the modern expensive methods, therefore, they prefer to extract the stone with cheaper and easier method. Keeping in view the financial condition of the mine owners a suitable method should be suggested which will be comparatively cheaper and easy to perform. Expansive method is one of these methods which could be applied in any terrain and environment with comparatively less cost

Expansive mortar. Expansive mortar, is also known as non-explosive demolition agent and is a silent cracking agent. It is basically made from calcium oxide $(\mathrm{CaO})$ which is responsible for the expansion from hydration. 

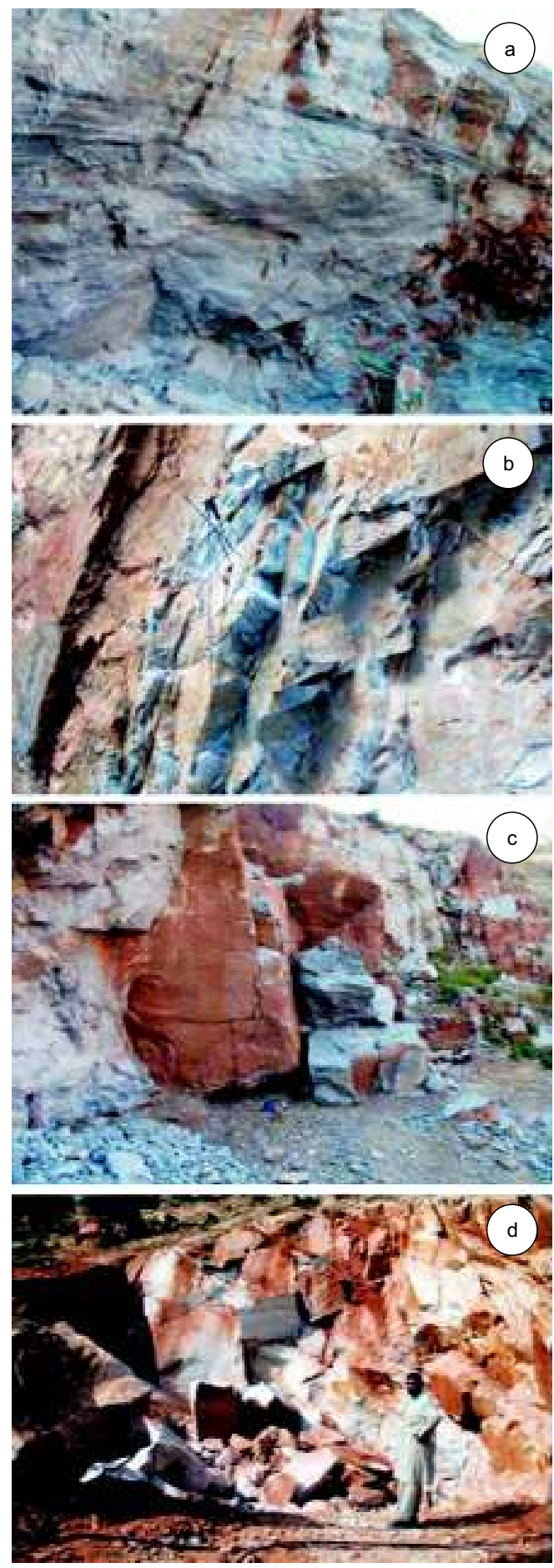

Fig. 2(a). Its view of high working face developed by blasting (b) Hanging drill machine can be seen in high working face that may lead to accidents (c) View of cracks developed as a result of blasting (d) induced cracks in mother rocks due to high intensity blast.
$\mathrm{CaO}+\mathrm{H}_{2} \mathrm{O} \rightarrow \mathrm{Ca}(\mathrm{OH})_{2}+15.2 \uparrow \quad(\mathrm{kCal} \mathrm{mol})$

Other components are also found in the mortars: $\mathrm{SiO}_{2}$, $\mathrm{MgO}$ and small amounts of $\mathrm{Fe}_{2} \mathrm{O}_{3}, \mathrm{Al}_{2} \mathrm{O}_{3}, \mathrm{Na}_{2} \mathrm{O}$ and $\mathrm{K}_{2} \mathrm{O}$ which upon hydration expands (Lucena et al., 2011). Expansive mortar when mixed with water produces up to $18,000 \mathrm{psi}$ expansive strength.

The companies producing expansive mortar are mainly located in Italy, Spain and China. SPLIT-AG a product from Xiamen Bestlink Factory Co, LTD China was used in this study.

When filled into holes, it cut rocks and reinforced concrete safely and quietly, while providing silent cracking. By properly designing drill holes, dimension blocks of desired shape and size can be excavated in an environment friendly manner unlike blasting. In mining industry of dimension stones, expansive mortars can play a vital role by achieving standard size blocks slabs without damaging remaining rock. Wastage rate of valuable stones using expansive mortar is negligible compared to blasting. It requires fewer technicalities and relatively much simple in operation. It can be used parallel with other methods, to multiply production and reduce the overall cost like, wire saw, detonating cord, hammers and chain saws (Dexpan 2012).

After filling holes by expansive mortar, it generates expansive waves stresses which increase with the passage of time. After $24 \mathrm{~h}$ the stresses reached to more than 11,000 tons $/ \mathrm{m}^{2}$ at room temperature. Expansive stresses are dependent on ambient temperature, in some cases it may generate required stresses earlier than defined by manufacturers due to changes in ambient temperature, by increasing temperature more amount of $\mathrm{Ca}(\mathrm{OH})_{2}$ is generated which creates significantly higher pressure (Natanzi et al., 2019). Expansive mortar works in three major steps (1) crack initiation Fig. 3 (2) propagation of crack Fig. 4 (3) increase in crack width (Crackamite, 2020). With introduction of expansive mortar's slurry into hole, it starts expansion. A tension creates in transverse direction and consequently a crack creates in the direction of the adjacent hole/free face. In the same way a crack develops from the other hole as well which then meets with the crack produced from the previous hole. In this a crack develop in the direction of holes which causes the block separation from the parent rock. 


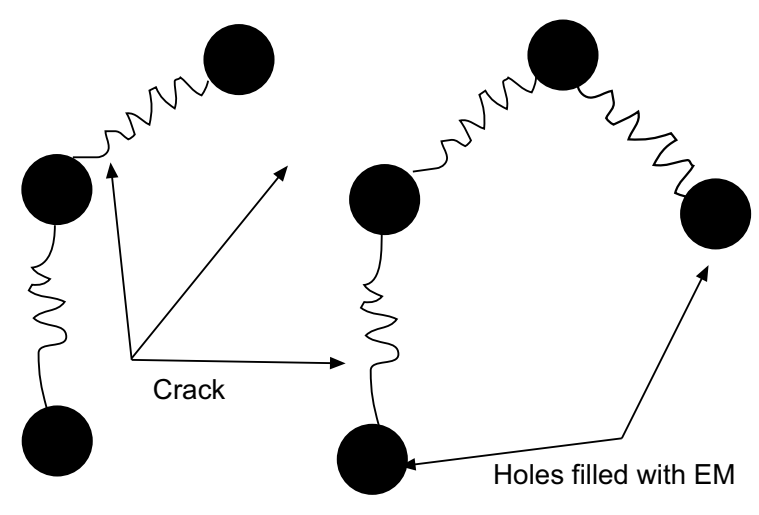

Fig. 3. Fracture mechanism by the expansive stress of EM.

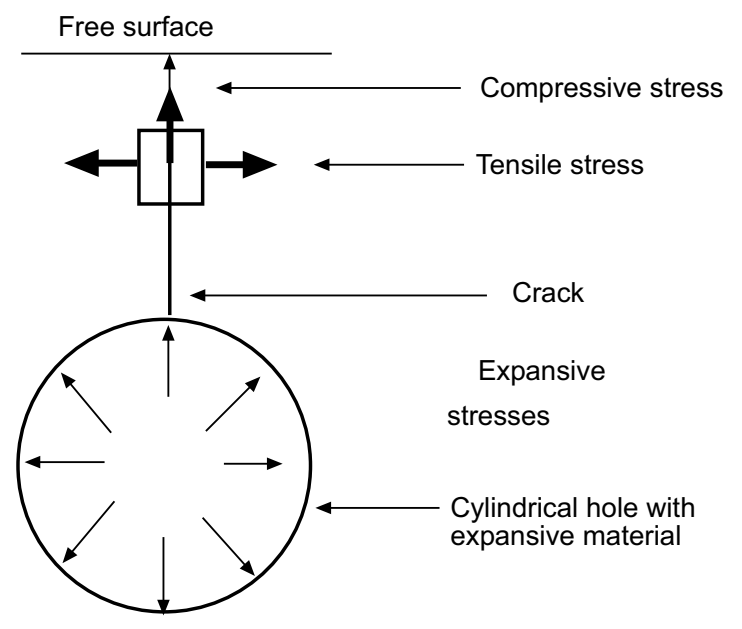

Fig. 4. Hole to hole crack propagation.

\section{Results and Discussion}

All the trails have been carried out in one mine of Pirkhel village district Malakand (KPK) (Lat. 34 .34' $.50^{\prime \prime} \mathrm{N}$; Long $71^{\circ} .48^{\prime} .27^{\prime \prime} \mathrm{E}$ ) in topographic sheet No. $38 \mathrm{~N} / 40$. The host rocks are calcareous rocks, having close contact with kalangi granite. Its average uniaxial compressive strength is $27 \mathrm{MPa}$. The marble is white to light gray and contains yellowish brown and green patches and also contains sparsely disseminated crystals of pyrite and chalcopyrite. The deposit is fractured and large blocks cannot be obtained by blasting.

In our trials the developmental and face preparation work observed in morning and all holes filled at evening time. For each trial a different design according to rock orientation has been used. Due to finances and time constraints nine numbers of trials has been carried out.
All the parameters were kept constant in this study except spacing between holes and depth of holes. Also drilling cost is associated with these parameters i.e. increase and decrease of hole depth and spacing will subsequently vary cost of drilling. The outcomes of nine trials are given in the Table 1. It can be observed from the Table that except trial 4, the face to be extracted is from 7 to $11 \mathrm{ft}$ long, from 5 to $7 \mathrm{ft}$ wide and 3.5 to approximately $6 \mathrm{ft}$ high. Depth of the holes is kept approximately $1 / 2 \mathrm{ft}$ less than the height of the blocks, to make sure that the crack reaches the bottom of the block. Number in each trial is from 6 to 8 except trial 4. It can be seen from the table that the drilling cost is $4.0 \$$ per foot, while the drilling cost per $\mathrm{ft}$ in the trial 4 is $4.1 \$$, which shows that the drilling cost per foot increases /decreases if the number of holes is increased. Similarly, expansive material cost also varies with the increase or decreases in the number of holes. The table also depicts that the income increases if the number of holes is increased.

Some of the blocks produced are shown in Fig. 5. It can be observed from the figure that despite the irregularly drilled holes, the expansive material produced a smooth crack in between the parent rock and excavated block. It can also be observed that there are no visible cracks in the produced blocks as produced in blasting procedures. The method can also be effectively used for splitting huge blocks to facilitate its transportation. The faces produced indicates that the waste production is minimum, which is a major concern in drilling and blasting technique. Moreover, handling of small sized regular shaped block, is easy as compared to potato/irregular shaped blocks, which we observe in blasting techniques. Regular shaped blocks yield in processing units is more than irregular blocks.

Comparison of conventional blasting and expansive mortar. The introduction of expansive Mortar gives positive results as compared to conventional blasting technique. For comparison purposes, a couple of tests were conducted in the same quarry. Table 2 shows comparison of the two methods. It can be observed from the Table that the difference in production is not that much but the market value changes the scenario. This is because of the fact that with explosives irregular blocks produced with excessive waste and cracks in the blocks, while the EM produces regular blocks with minimal waste. Therefore, results of expansive mortar are more prominent with large benefit than blasting 

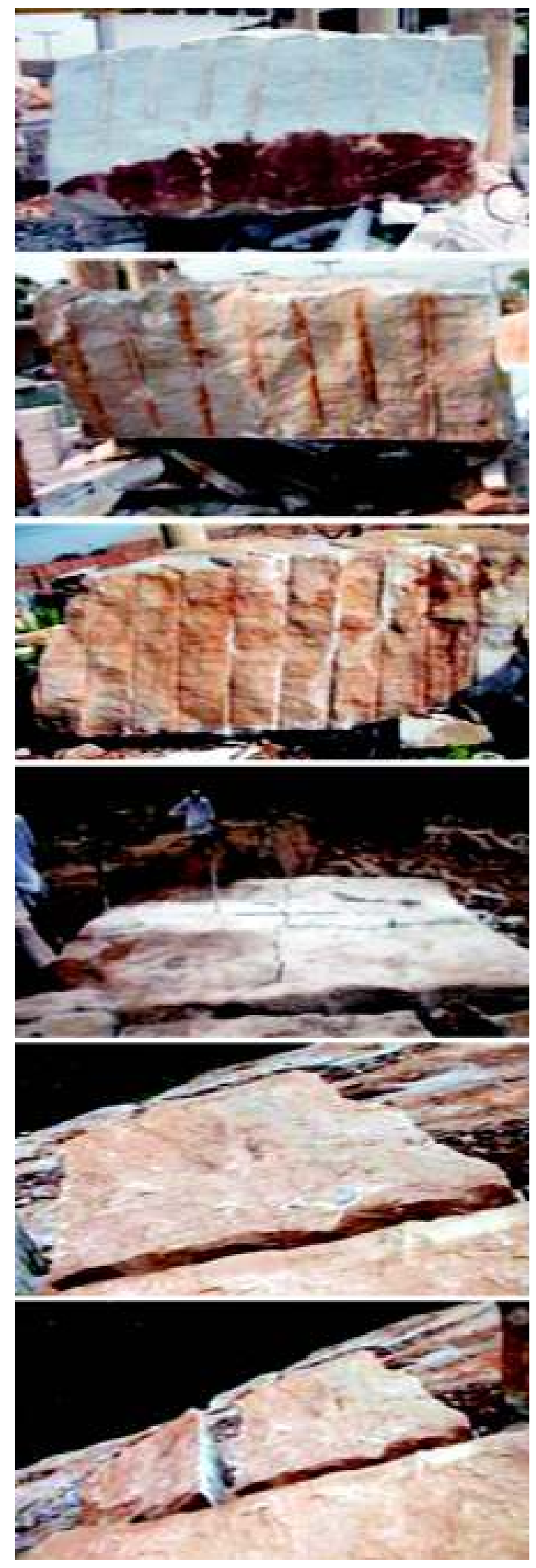

Fig. 5. Random photographs of different blocks from trial studies. technique. It can be seen from Table 2, that although the depth of holes in the blasting techniques are more as compared to EM method, but the production of blocks in EM method is reasonably better than blasting technique. Although there two blocks of blasting are shown in the Table, but still 489 MTs blocks are produced in EM method which in two blasts, only 470 MTs blocks are produced. The cracks also witnessed in the blasting technique which can be observed in Fig. 2. Moreover, the table show that there is no production of small blocks and waste while waste and small blocks were produced in the blasts. The semi blocks produced in the EM and blasting techniques were 19 MTs and 30 MTs respectively, which also depicts the advantage of the EM method. It can be noticed from the table that although the drilling and EM cost is more than the drilling and explosive cost but still the EM method is more economical than blasting technique. The total revenue that is generated from the EM is about $\$ 5766,46$ while two blasts of explosive method yielded only about $\$ 1122$ which is about five times less than EM revenue. The comparison of the revenue generated is also presented in Fig. 6. Apart from economic benefit, we need to consider the hazards associated with the use of blasting method, such as fly rock, ground vibration, dissociation of free laying rock in the face above the workers, which can fall any time over the workers and may cause serious injury, waste produced due to irregular shaped blocks at processing unit is too hazardous and may lead to tuberculosis and cancer among the labors and managers (Khan et al., 2015). It has been observed that more than 10 fatal accidents occurred from 1993 to 2020 in marble mines of district Buner only due to sliding of the overlying rocks over the people and more than 20 fatal accidents from the use of explosives. (Details of Mines Accidents in District Buner Since

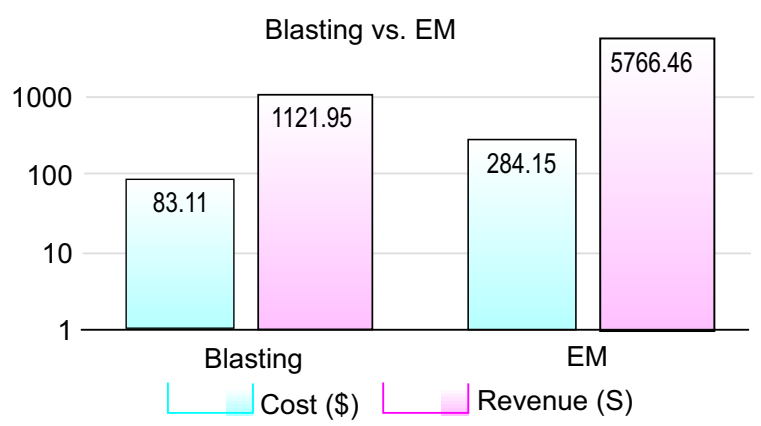

Fig. 6. The comparasion of the revenue generated. 
Table 1. Conditions and results of all trials are given with their respective cost and profit

\begin{tabular}{lllllllllll}
\hline \hline Parameter & Unit & Trial 1 & Trial 2 & Trial 3 & Trial 4 & Trial 5 & Trial 6 & Trial 7 & Trial 8 & Trial 9 \\
\hline Length & $\mathrm{ft}$ & 8.25 & 8 & 9.25 & 50 & 11 & 10 & 10 & 8 & 7.5 \\
Width & $\mathrm{ft}$ & 5.33 & 6.5 & 5.33 & 18 & 5 & 5 & 2.5 & 7 & 7 \\
Height & $\mathrm{ft}$ & 4.75 & 4.25 & 5.75 & 7.5 & 5 & 5.58 & 4 & 3.5 & 5 \\
Spacing & $\mathrm{in}$ & 11 & 12 & 11.5 & 10 & 12 & 12 & 12 & 15 & 12 \\
Depth of holes & $\mathrm{ft}$ & 4 & 3.67 & 5 & 6.5 & 4.5 & 5 & 3.5 & 3.2 & 4.5 \\
No. of drill holes & $\mathrm{No}$ & 7 & 7 & 9 & 60 & 10 & 10 & 8 & 6 & 6 \\
Total drilling & $\mathrm{ft}$ & 28 & 26.5 & 45 & 390 & 45 & 50 & 28 & 19 & 27 \\
Drilling cost & $\$$ & 6.83 & 6.49 & 11.0 & 95.1 & 11.0 & 12.2 & 6.8 & 4.6 & 6.6 \\
EM cost & $\$$ & 14.0 & 13.0 & 22.0 & 189.0 & 12.2 & 24.4 & 13.7 & 9.3 & 13.2 \\
Total cost & $\$$ & 20.9 & 19.5 & 32.9 & 284.1 & 23.2 & 36.6 & 20.5 & 13.9 & 19.8 \\
Total production & $\mathrm{MTs}$ & 11 & 13 & 16 & 489 & 19 & 18 & 8.5 & 14 & 19 \\
Income & $\$$ & 201.2 & 237.8 & 292.7 & 5766.5 & 347.6 & 329.3 & 152.4 & 256.1 & 347.6 \\
\hline
\end{tabular}

*Conversion factor: PKR to USD is $1 \mathrm{USD}=$ Rs. 164.0

Table 2. Comparison of conventional technique and expansive mortar

\begin{tabular}{|c|c|c|}
\hline & Blasting & Expansion material \\
\hline Block dimension & $\begin{array}{l}40 \times 16 \times 11 \text { and } \\
26 \times 13 \times 11\end{array}$ & $50 \times 18 \times 7.5$ \\
\hline Total area in volume & 10758 cubic ft. & 6750 cubic ft. \\
\hline No. of drill holes & 29 & 60 \\
\hline Depth of hole & $16 \mathrm{ft}$ and $13 \mathrm{ft}$. & $6.5 \mathrm{ft}$. \\
\hline Total drilling & 431 linear feet & 390 linear feet \\
\hline Drilling cost & $431 \times 20=$ & $\begin{aligned} 390 \times 40= & \$ 95.12 /- \\
& \$ 52.56 /-\end{aligned}$ \\
\hline $\begin{array}{l}\text { Explosive cost/ } \\
\text { EM cost }\end{array}$ & $\$ 30.55 /-$ & $155 \mathrm{~kg}=\$ 189.02 /-$ \\
\hline Total cost & $\$ 83.11 /-$ & $\begin{array}{l}\text { Total cost }=\$ 284 \\
15 /-\end{array}$ \\
\hline Total production & 470 MTs & 489MTs \\
\hline $\begin{array}{l}\text { Small blocks and } \\
\text { waste }\end{array}$ & Yes & No \\
\hline Blocks & 440 MTs & 470MTs \\
\hline \multirow[t]{2}{*}{ Semi Blocks } & 30MTs & 19MTs \\
\hline & Pricing & \\
\hline Irregular block rate & $\$ 2.44 / \mathrm{MTs}$ & $\$ 4.88 / \mathrm{MTs}$ \\
\hline $\begin{array}{l}\text { Semi/cubic } \\
\text { Block rates }\end{array}$ & $\$ 1.22 / \mathrm{MTs}$ & $\$ 12.20 / \mathrm{MTs}$ \\
\hline Blocks & $\$ 1073.17 /-$ & $\begin{array}{l}\text { 470Tons } \times 2000=\$ \\
5731.71 /-\end{array}$ \\
\hline Semi block & $\$ 48.78 /-$ & $\begin{array}{l}\text { 19Tons } \mathrm{x} 400=\$ 34 . \\
76 /-\end{array}$ \\
\hline Total revenue & $\$ 1121.95 /-$ & $\$ 5766.46 /-$ \\
\hline
\end{tabular}

1993 to Sep, 2020, 2020) Smoke and dust production are other problems associated with blasting. On the other hand, use of EM is safer, there is no danger of any issue discussed earlier in the blasting technique.

On the basis of the above discussion it can be concluded that the EM method is more productive, economical, safer, easy to carry out and does not need any specialized expensive equipment such as diamond wire saw/ or chain saw etc.

\section{Conclusion and Recommendations}

Regular shaped blocks free of any cracks are guaranteed to be produced by the use of expansive mortar. Waste produced is of negligible amount and can be used as semi blocks. Expansive mortar is much profitable than blasting technique. Good quarry maintenance is possible with the use of expansive mortar. Average spacing of 5.6 to 8.5 times hole diameter and depth of hole of 80 to $95 \%$ of desired block height respectively are found suitable parameters for intact rock. Average spacing of 7.1 to 10.6 times hole diameter and depth of hole from 90 to $100 \%$ of the desired block height are found appropriate parameters for splitting of extracted blocks.

Based on the fruitful results from field tests and positive response from stakeholders, it is suggested that some regulations must be made by government for use of expansive mortar instead of blasting. Seminars and workshops are needed on national level for familiarization of the expansive mortar among all stockholders (i.e. mine owners, operators, and workers). Further research is required to optimize various parameters like drilling variables including hole depth, spacing, burden, hole diameter and inclination. Site specific characteristics also needed to be investigated by conducting trials in different localities.

Conflict of Interest. The authors declare no conflict of interest. 


\section{References}

Asrarullah, Hussain, A. 1985. Marble deposits of north west frontier province, Pakistan. Geological Survey of Pakistan, Information Release, No. 128.

Bhandari, S.,Rother, S. S. 2001. Extraction of marble blocks by controlled blasting techniques-A case study. Mine Planning and Equipment Selection, 295-302.

Bilqees, R., Hussain, A., Pasha, A. R.,Husain, V. 2017. Marble deposits of Khyber Pakhtunkhwa and FATA, Pakistan. International Journal of Economic and Enviromental Geology, 8: 28-32.

Crackamite. 2020. https://www.crackamite.com/working

Details of Mines Accidents in District Buner Since 1993 to Sep, 2020. 2020.

Dexpan. 2012. https://www.dexpan.com

Khan, M.A., Rehman, S.U.,Rahman, A. 2019. Sustainability analysis of marble sector in Buner. International Journal of Economic and Enviromental Geology, 10: 94-101.

Khan, Q., Maqsood, S., Khattak, S.B., Omair, M., Hussain, A. 2015. Evaluation of activity hazards in marble industry of Pakistan. International Journal of Engineering \& Technology IJET IJENS, 15: 73-78.

Korai, M. A. 2010. A report on marble and granite. In: Trade Development Authority of Pakistan. https:// www.tdap.gov.pk/doc_reports/tdap_report_on_m arble_and_granite.pdf
Lucena, D.V., Campos, D.B.C., Lira, H.L., Neves, G.A. 2011. Synthesis of expansive mortar developed in laboratory for dismounting of ornamental rocks. IOP Conference Series: Materials Science and Engineering, 18: (SYMPOSIUM 1). https://doi.org/ 10.1088/1757-899X/18/2/022009

Mansoor, Y. 2012. Pakistan marble industry challenges: opportunities for China in Pakistan. Journal of Independent Studies and Research-Management, Social Sciences and Economics, 10: 43-59. https:// doi.org/10.31384/jisrmsse/2012.10.1.4

Natanzi, A.S., Laefer, D.F., Kakali, G., Iman Zolanvari, S.M. 2019. Temperature-induced chemical changes in soundless chemical demolition agents. Journal of Materials in Civil Engineering, 31: 04019098. https://doi.org/10.1061/(ASCE)MT. 19435533.0002653

Pakistan Financial Services Sector Reform Programme (PFSSRP) Report. 2007. Cluster Mapping of Pakistan's Marble Sector (NWFP), A Project Funded by European Union and Implemented by Innovative Marketing Services (IMS), Pakistan, 22-31.

SBI. 2010. Pre-Feasibility Study - Marble Quarry Project. https://sindhinvestment.gos.pk/Feasibility/ marble-quarry-project.pdf

SMEDA. 2010. Marble and Granite Sector Development Plan. http://www.irispunjab.gov.pk/StatisticalReport /Manufacturing Industry Data/Marble and Granite Sector development plan.pdf 